\title{
Nurturing Autonomy in student midwives within a student led antenatal clinic
}

\begin{abstract}
Background: A clinical environment that provides meaningful and productive learning experiences is essential for students of all health care professions. To support the learning needs of undergraduate midwifery students and facilitate the continuity of care experiences a student led clinic was established in one South East Queensland maternity unit.
\end{abstract}

Aim: This study explored the experiences and learning processes of previous and current midwifery students undertaking clinical practice within a student led clinic.

Method: Qualitative descriptive. Ten students that elected to work in the midwifery student led clinic were invited to participate in a one off digitally recorded face to face or telephone interview. Thematic analysis was used to analyse the data set. University ethical approval was granted (NRS/17/15/HREC).

Findings: Findings suggest the student led clinic positioned students in the 'driver's seat'. Overwhelmingly students described the clinic as providing them with an array of opportunities to 'lead' care rather than being forced to 'sit and watch'. Students believed the experience of working in the clinic increased their midwifery knowledge, skills, confidence, critical thinking, and the ability to advocate for and empower women.

Conclusion: High quality and supportive clinical teaching and learning experiences are vital for ensuring the student midwife develops into a competent practitioner who is fit for registration. The evidence from this small study highlights the benefits afforded to students of working in partnership not only with pregnant women but also with their university midwifery lecturer. The student's continuity of care learning experiences appeared to foster and cultivate their capability, identity, purpose, resourcefulness and connection; all the five senses of success. 


\section{Keywords}

Midwifery student

Antenatal Clinic

Experiences

Continuity of Care

Statement of Purpose

\begin{tabular}{|l|l|}
\hline Problem or Issue & $\begin{array}{l}\text { There is a paucity of research on the experiences of student } \\
\text { midwives working within a student led antenatal clinic }\end{array}$ \\
\hline What is Already Known & $\begin{array}{l}\text { Midwifery students enrolled in an undergraduate programme } \\
\text { require learning environments that provide meaningful and } \\
\text { productive learning experiences. }\end{array}$ \\
\hline What this Paper Adds & $\begin{array}{l}\text { The student led antenatal clinic offered students an } \\
\text { opportunity to care for their continuity of care woman within a } \\
\text { supportive environment where they were afforded the ability } \\
\text { take on the role of the primary caregiver while being } \\
\text { supervised by a registered midwife. Students communicated } \\
\text { that their experiences within the student led clinic promoted } \\
\text { confidence, competence, and a sense of autonomy and } \\
\text { prepared them well for the transition to practice as a } \\
\text { registered midwife. }\end{array}$ \\
\hline
\end{tabular}

\section{Introduction}

In Australia, midwifery students spend approximately $50 \%$ of their time in clinical practice. The clinical practice experience, and the environment in which it takes place is therefore a 
pivotal part of the student's adult learning experience (1). High quality and supportive clinical teaching and learning experiences are vital for ensuring the midwifery student develops into a competent practitioner who is fit for registration (1). Carter and Wilkes (2) using a descriptive cohort study identified, some challenges associated with students providing continuity of care $(\mathrm{CoC})$, proposing that new learning strategies within a midwifery curriculum should be created to support students who practise within a CoC model. Recommendations included the importance of constructing a clinical environment which is supportive, with effective communication between all stakeholders. A key challenge facing all universities teaching undergraduate midwifery students is access to quality clinical experiences that are woman centred, philosophically aligned, promote continuity and are evidenced based.

Currently, there is a paucity of research available on midwifery students experiences of providing continuity of care to women in a student led clinic supported by midwives and/or practice lecturers. Therefore, this study was designed to address this gap in knowledge. It is also recommended due to the limited amount of research available that further research is recommended.

\section{Context}

To support the learning needs of undergraduate midwifery students and facilitate the continuity of care experiences a student led antenatal clinic (SLANC) was established in one South East Queensland maternity unit. The SLANC was a collaborative effort between a University and a Maternity Service Facility and was developed to specifically support midwifery students in providing continuity of care to childbearing women. Initially the SLANC was only designed to provide antenatal care to women, however in 2016 postnatal appointments were also offered. The clinic is located within the antenatal services of a large tertiary referral centre in South East Queensland. During the antenatal and postnatal appointments, the students are supported in a preceptorship model by their University Practice Lectures. The students are 'on call' for the woman's labour and birth and preceptored and supported by registered midwives working within Birth Suite. The role of the Practice Lecturer $(P L)$ is to support, encourage and 
role model midwifery along with providing opportunities for debriefing and reflection. As well as the university practice lecturer supporting the midwifery student within the clinical setting there was an added value of strengthening the relationship between the university and the practice site (1).

\section{Aim}

The aim of this study was to explore the experiences of previous and current midwifery students who provided continuity of care to women in a student led antenatal clinic (SLANC) supported by their University Practice Lecturer.

\section{Methods}

A descriptive qualitative approach was used in this study. This method is particularly useful in the context of health care as it provides real life answers to how people feel about a particular situation or environment and what factors might impact their experiences (3).

\section{Setting}

The student led antenatal clinic was set up as a collaboration between a large Maternity unit in South East Queensland and a Queensland University. The SLANC was set up within the antenatal clinic of the maternity unit which contains 14 consultation rooms, 5 outreach clinics, and services approximately 6,000 pregnant women per year. The SLANC consulting rooms were in the antenatal clinic of the hospital and therefore were a familiar learning environment to the students. The first year of the project focused on developing process and refining systems to support the successful implementation of the clinic. This required guest access and training of practice lecturers to the Electronic Medical Record (EMR) system, Maternity information system (MATIS), and the Hospital Based Corporate Information Systems (HBICS).

At the onset of the SLANC a media release was activated to bring about an awareness of this specialised ANC that was led by midwifery students. The practice lecturers who were interviewed emphasised that the collaboration between the Maternity unit in South East 
Queensland and the university represented a unique partnership which focuses on the continuity of care for expectant mothers and a high quality learning experience for the students. Initially the SLANC was only available on a Friday afternoon, but increased its availability to women three afternoons a week.

The main purpose of the clinic was to enhance student learning by:

- $\quad$ Providing a supportive teaching and learning space, free from time pressures, for midwifery students to provide antenatal care for women who they were in a Continuity of Care (CoC) relationship (in essence enhance the CoC experience),

- $\quad$ Providing an opportunity for the university's PL's to work alongside students, in a reallife clinical environment, role modelling professional behaviours, helping students translate their theoretical knowledge into clinical practice.

- $\quad$ Assessing student's clinical midwifery knowledge and skills as well as evaluating their communication and decision-making skills including consultation and referral,

- $\quad$ Strengthen the relationship between the University and the Maternity unit.

\section{Participants and recruitment}

Following ethical approval (Ref No: NRS/17/15/HREC) current and past midwifery students who had utilised the clinic were invited to participate in the study via e-mail. An information sheet and consent form were attached. Participants were asked to contact the research team if they were interested in being involved. All 10 participants consented to the study after which a time and place suitable to the participant was made to conduct a digitally recorded interview (Table 1.).

\section{Data collection}


The semi-structured interviews were undertaken in August 2017 and lasted between 40 and 60 minutes. Three of the interviews were conducted by telephone and seven were face to face. Prior to commencing the interviews consent was reaffirmed and a number of demographic questions were asked of the participant (for example age, year level). While the researchers adopted an informal and conversational style encouraging participants to express themselves openly (4) a number of open-ended promoting questions were developed to guide the interviews and maintain consistency across the two researchers collecting the data.

\section{Data Analysis}

This study used a qualitative descriptive analysis design. Qualitative description is particularly useful to health environments, because it provides real life responses to questions about how people feel about a particular environment, what reasons they have for accessing this environment, who is using the particular services of this environment and what factors facilitate or hinder this environment (3). Individual interviews were conducted with the participants as the researcher wanted to explore in-depth the experiences of students who had participated in the SLANC (5). Each of the participants completed a semi-structured interview of between 40-60 minutes with the researcher. The interviews were conducted face to face or by telephone. A semi-structured interview guide was used containing some demographic and open-ended questions. The format of semi-structured interviews involve a few pre-determined areas of interest with possible prompts or cues from the researcher to help guide the conversation (5).

Thematic analysis was used to analyse the data (4). Each interview transcript was read several times by the $1^{\text {st }}$ author in order to become familiar with the data. Initially codes were generated to transform raw data into a standardised format and recorded as individual notes by the researcher. This coding of the data involved identifying recurrent words, concepts or 
themes. Coding continued across all transcripts until potential patterns emerged. Potential patterns emerged by the continual examination and exploration of similarity or overlaps within the codes or concepts and the relevance to the entire data set. As the data analysis continued over time and became more refined stronger themes developed. As themes and sub themes developed from the data a thematic map was created to explore and refine the connections further. By using thematic analysis, a systematic qualitative, detailed and nuanced account of the data was produced (6). Thematic analysis has a factist perspective, in that it assumes the data to be truthful or more or less accurate to the reality in the world (7). Therefore, thematic analysis was appropriate for this study because it is a coherent integration of the disparate pieces of data that captures something important in relation to the research question $(6,7)$.

\section{Trustworthiness}

As four of the ten participants had worked with the main researcher in the SLANC another researcher (author 2) was appointed to interview these participants to avoid any bias and strengthen the trustworthiness of the data. The same semi- structured interview guide was used by both researchers.

\section{Ethics}

Ethical approval was obtained from the Universities Human Research Ethics Committee via the student life cycle (Ref No: NRS/17/15/HREC). Along with the consent form a plain English information sheet was also emailed to the participants explaining the purpose of the study, confirming confidentiality and containing contact details of the research supervisor if any concerns were raised. Anonymity of the participants was assured and a pseudonym was allocated to each participant. The participants were well aware that their participation 
was voluntary and confidentiality was discussed including the possibility that direct quotes from the interview could be used within the findings of the study.

\section{Findings}

\section{Participant characteristics}

The ten participants who participated in the study, were all female and aged between 20 and 44 years of age. Eight were graduate midwives in their first year of practice and two were current second year midwifery students enrolled in the Bachelor of Midwifery degree. All the graduate midwives had utilised the student led clinic throughout their clinical practice placement as a midwifery student at the university. Of the ten participants, seven had a previous qualification prior to studying to become a midwife. All the newly graduated midwives were employed in a tertiary teaching hospital either in Queensland or New South Wales.

\section{Theme: Being in the 'driver's seat'}

The major theme elicited during the analysis process was labelled, 'Being in the Driver's Seat'. In essence, this spoke to the student's perceptions that working in the student led clinic enhanced their sense of engagement during the clinical practice experience. Participants talked about feeling 'in control' of their own clinical experience. This was a concept that all the participants highlighted and was juxtaposed to other commonly cited experiences where, as students, they described 'just sitting and watching a lot of their time' (Mary). Participating in the clinic provided students with the opportunity to manage the women's appointments and undertake care planning. Students described being expected to 'step up' and 'lead' the care with support from the practice lecturer. As a result, they talked about how working in the clinic engendered the feeling of being a 'real midwife'. Even as a first-year student Robyn described her learning experience as very positive; 
"It suits me much better rather than just sitting and observing, which is sort of the capacity that we would be normally doing antenatal clinics as a first year student midwife. So, I liked being the lead and I felt like I was learning more."

Participants articulated how being immersed in the 'role of the midwife', with a level of support, was incredibly beneficial to their learning, facilitating the development of their clinical judgement, midwifery skills and autonomy. The responsibility of taking the lead role in the care of the woman throughout the appointment appeared to enhance the student's own agency. Student's acknowledged that having the 'freedom' to be able to 'run' the appointment and provide a complete physical, emotional and social assessment of the woman contributed to their growing level of confidence and competence. Having the opportunity to take responsibility for all the assessments during the appointment while listening to women's concerns and responding to their questions gave the students the ability to integrate theory with practice and enhanced their feeling of being able to competently enact their role. In turn students felt this fostered their independence and enhanced their critical thinking skills;

"More like the reins were handed over to you. As a student to actually provide the care and complete the assessment and answer the questions, and discuss things with the woman, and do the critical thinking yourself, rather than sort of being spoon fed... it makes you more independent as well" (Elouise).

Participants were resolute that working in this way facilitated greater rapport building and trust with women, which enhanced their ability to learn from, and with women, it also allowed them to provide continuity of care that was tailored to the woman's individual needs and preferences. Students were delighted that they were able to provide what they considered to be 'holistic woman centred midwifery care'. They also believed that their increased levels of confidence translated into an enhanced ability to support women not only during pregnancy but also during the labour and birth process. As Bonnie expressed; 
"So, yeah, I definitely think it's made me more confident with the women, and more confident to advocate for the women and in the birth as well."

Taking on the role as the primary care provider supported by the practice lecturer, also provided the students an opportunity to truly 'test out' the midwife they espoused to be. Having the opportunity to align their philosophy with their practice, as opposed to mimicking the practice of other midwives, was highly regarded and promoted further reflection on their roles and responsibilities. Working in the clinic appeared to have consolidated the participants' sense of themselves as midwives and of how midwifery should be practiced and the way they needed to be with the woman to enact this. Linda clearly recognised this when she said;

"I had the pseudo experience of working towards my role, my identity, my practice as an individual midwife, and not just take on the persona of other midwives that are in clinic."

Participants also felt they gained real 'practical' knowledge of systems and processes as they had responsibility for the smooth running of the clinic. Developing a clear understanding of how the clinic functioned and mastering processes increased the students' sense they were well prepared for graduation,

"Oh, I thought it was excellent. I thought it gave me real hands on with the computer systems, because I felt that out of everything to prepare us for going to work, not having access to the computers was one of my major concerns" (Donna).

Ultimately, students recognised how their experiences in the clinic contributed to their growing level of confidence and competence.

"I have to say it was a very big confidence boost for me. I could definitely go home and reflect and visualise myself as a registered midwife" (Linda). In addition, all felt the experience was excellent preparation for working as a graduate midwife; "It's just being in the driver's seat, it just gives you a snippet of what it's going to be like next year ... sort of sets the scene for when you're on your own" (Esther). 


\section{Factors that enhanced / facilitated the students' experience}

\section{Practice Lecturer: Nurturer in the background}

When initially talking about their experiences of the student led clinic all the participants commenced with a discussion around the supportive role the university practice lecturer played in assisting them to gain the most out of the experience. For the most part, the practice lecturers were considered to offer students an unobtrusive supportive 'presence'. Esther's comment is reflective of many;

"So, the lecturer just sits back, it's your appointment effectively, they're just there to support you."

Students felt that when the practice lecturers positioned themselves in this way, they were afforded the 'freedom' to be themselves and 'manage' the appointment on their own while at the same time when required receiving support and gentle guidance. The students expressed being acutely aware that they 'didn't know everything' but found working closely with their midwifery lecturer (as a 'second pair of eyes and ears' in the room) facilitated their ability to rehearse information sharing, supported informed decision making and helped them to gain confidence in their own clinical and communication skills. Bonnie expressed it like this;

"Obviously I don't know all of the things, so with the lecturer as well we were kind of working together - it felt much more like we were working together and it didn't feel so student like".

The expectation that with support the students would lead the care, provided the students with the opportunity to truly experience what it might be like to be a registered midwife. In this way, the student was afforded an opportunity to experience working in partnership with the woman with the 'silent' support of a practice lecturer. As expressed by Tilly;

"I think just being able to role play as a midwife - I didn't feel like a midwife, especially in first and second year, but to be able to role play as a midwife knowing that you were supported 
was really good." Similarly, Mary alleged; "It was a great experience to fully take on the role as a midwife knowing that you've got support behind you, if you need it."

Working alongside their practice lecturers, who they considered were experts in their field, was initially 'daunting' for some students and 'confronting' for others. Students commonly worried about being 'judged' for what they may not know. However, following their first experience of the clinic and working alongside the practice lecturer students stated they relaxed and quickly came to appreciate their role;

"Having the lecturers there, and they're completely non-judgemental, they're there to support you, which is great" (Felicity).

Students came to enjoy working alongside their practice lecturer and soon realised the advantage of having a preceptor they perceived as woman centred, knowledgeable about the program requirements and 'in tune' with their learning needs and progress. As Monty reiterated during her interview;

"I feel like because they're lecturers from the Uni, they're more in touch with what we needed to do as a student to get a grip on our role." Tilly reinforced; "The lecturers would think, okay, you're a first year, or okay you're a second year, you should know these steps."

As such the students felt that having this personal knowledge facilitated the practice lecturer's ability to offer appropriate cues or prompts at opportune times during the appointment;

"The lecturer had to remind and support me to delve into particular information more. I'm not sure I would have remembered to do it if she hadn't prompted me" (Linda).

Another important feature of the clinic structure was the ability for students to spend individual and private time with their practice lecturer, both before and after the woman's appointment. Students expressed that they found it 'incredibly' beneficial being able to talk through the woman's situation, revisit the clinical history with the practice lecturer and then plan how they 
may manage the appointment. This subsequently included reflecting on how the appointment unfolded and the critical learning points elicited from the experience;

"It was good at the end of the appointment, after l'd said goodbye to the woman, I then went back in and debriefed with the midwife lecturer" (Felicity).

Being able to participate in regular structured reflections of this nature was considered fundamental to the students learning. Students commonly expressed how this was a unique feature of the clinic, really helping to consolidate knowledge as well as integrating theory with practice. This was something they rarely experienced when working alongside other registered midwives or clinicians during regular clinical practice placements. The following comment by Elouise is reminiscent of many others;

"I think the fact that there was always opportunity to reflect and debrief with the lecturer after the appointment was excellent. Certainly, not something that you usually get to do in the other models of care."

\section{'Time' to provide holistic continuity of midwifery care}

Another feature of the clinic that enhanced the student experience was the extended and flexible appointment times. All the students greatly valued the extra time available to them to conduct their antenatal appointments with women. Unlike their previous experiences in the 'normal' hospital antenatal clinic or with the GP the student clinic offered an environment where students did not feel 'pressured' to 'rush' women through their appointments;

"I suppose for me the biggest benefit that I can recall was being able to sort of take a bit more time with the women" (Elouise).

Students revelled in the knowledge that women had plenty of time to ask questions and they had ample time to engage in meaningful dialogue and information sharing that would meet women's needs. Students regularly expressed how satisfying this was as opposed to what 
they perceived was commonly a 'tick box' exercise in other antenatal contexts. As Bonnie remarks,

"With the student clinic we have more time, and I think that also helps and they can talk about what they need to rather than what's on the piece of paper".

Having time to work through issues with a woman and to be able to think through just what she needed from the visit was also important. As Tilly said,

"I think you have to keep that extra appointment time because as students we take longer to do things".

Students shared how the calm and flexible environment minimised the pressure they themselves often felt to 'correctly' complete assessments in front of other clinicians. The additional time students were able to 'be with' women translated into increased opportunities to listen, explore issues, initiate what might be potentially difficult questions and practice their assessment skills. The following quote from Elouise speaks to this;

"You had time to dig a bit deeper when a woman had a question or a problem or something like that, rather than just brushing over it, like often happens in usual antenatal appointments." As a consequence, students were able to deeply engage with women. In turn, the students felt that this helped to create a safe space where the women felt able to be express themselves;

"It was really beneficial for the woman. I just think the women feel just more comfortable and just feel that they're really being listened too as well" (Monty).

This was especially revealing when significant emotional and/or domestic issues where disclosed. The extra 'time' afforded to both the woman and the student facilitated the student's ability to genuinely come to understand the woman's circumstances and personal situation. Students believed by having extra time to spend with women allowed for a deeper interaction 
and understanding to develop between the woman and themselves. They also felt their ability to connect with the woman was enhanced;

"I feel like there's a lot more rapport building, warmness, time and stuff in the student-led clinic." (Robyn). Students perceived they were much more able to provide holistic woman centred care to the continuity women in their care;

"I felt that there wasn't as much time pressure with the women. There was much more time to be holistic, to consider wholly, not just her clinical reasons for being there. When you're in the student led clinic, you know the woman and she knows you, so I think that there's much more of a trusting relationship, where she feels much more comfortable to reveal those things because she knows you're in a position to facilitate support and help" (Linda).

\section{Autonomy: Growing in Confidence and feeling Empowered}

The final subtheme that contributed to the overarching theme is 'Growing in confidence and feeling empowered'. This sub-theme clusters together all the data that speaks to the importance of taking a lead role in the woman's care, which in turn provided the students with the opportunity to grow in confidence. The responsibility of taking the lead role in the care of the woman throughout the appointment appeared to enhance the students own agency. Student's acknowledged that having the 'freedom' to be able to 'run' the appointment and provide a complete physical, emotional and social assessment of the woman, fostered their independence and enhanced their critical thinking skills;

"I think as a student it's really important to be able to take the lead and be able to do most of the appointment, you know, to benefit you when you leave, because not putting it all together as a student, it's quite hard when you go into your grad year" (Monty).

Students recognised how this contributed to their growing level of confidence and competence. Students believed that their increased levels of confidence translated into an enhanced ability to advocate for women not only during pregnancy but also during the labour and birth process. Bonnie expressed this well; 
"So, yeah, I definitely think it's made me more confident with the women, and more confident to advocate for the women and in the birth as well."

The increased level of autonomy, confidence and competence working in the clinic bestowed on the student, helped them to visualise themselves as 'registered' midwives. The experience of having the opportunity to do holistic assessments of women while listening to their concerns and responding to their questions gave the students the opportunity to practice being the midwife they want to be in the future. Linda portrayed this very clearly; "I have to say it was a very big confidence boost for me. I could definitely go home and reflect and visualise myself as a registered midwife."

Some of the students firmly believed that the environment of the student led clinic was a key aspect to their learning, so much so that they would leave the clinic feeling uplifted and motivated;

"I never went home from a student led clinic appointment thinking or feeling demoted or depleted or anything, I thought it was a good learning experience for me, definitely" (Felicity).

Overall students expressed that being able to take 'the lead' or 'sit in the chair' of the midwife gave them the opportunity to feel like a midwife, develop their midwifery skills and clinical judgement. This ownership of identity as a future midwife strengthened their confidence and their autonomy. Overall the confidence students gained from participating in a student led clinic appeared to enhance the student transitioning into practice.

\section{Discussion}

This study has provided insight into one clinical placement model that ensured midwifery students had a quality clinical practice experience. All new graduates and students who participated in the student led clinic described their experience as beneficial to their learning 
and skill development whilst integrating theory into practice and promoting confidence, competence and a sense of professional identity.

The overarching theme, 'being in the driver's seat' captured the student's sense of autonomy that working in the clinic bestowed on them. The practice lecturer's support, encouragement and role modelling along with opportunities for reflection were pivotal, as was the student's ability to be hands on. This facilitated a supportive experiential learning environment enabling the integration of theory and practice. Maxwell, Black (1) in their study also found that having a practice educator in a clinical setting supporting students bridged, what is commonly referred to as, the theory-practice divide. Likewise, in the qualitative study by Miller, Thompson (8) where students had access to a university practice lecturer in the clinical area, students reported being afforded a deeper understanding of how theory underpinned quality clinical practice.

The PL provided the students with a known and supportive practitioner, who was aware of their learning needs and ideally placed to support the integration of theory into practice. Miller, Thompson (8) propose that the role of the lecturer-practitioner is ideally suited to influence curriculum to suit the needs of the practice site, while also delivering evidence-based practice into the clinical area.

The student led clinic could also be described as a controlled learning environment where a pedagogical framework supported the student midwives learning experiences (9). Blackmore (10) describes a pedagogical framework as having four interrelated dimensions of critical thinking, dialogue, reflection and responsible action. Within the environment of the student led clinic midwifery students were given the opportunity to develop their critical thinking skills, enter into dialogue with women, plan care in collaboration with them and reflect on practice with their practice lecturers; all elements required to integrate theory into practice. In addition, the university practice lecturers were, as Lofstrom and Nevgi (11) have suggested they should 
be, perceived by students to be student focused, enacting a learning centred approach to teaching which speaks to pedagogical awareness.

Within the student led clinic the midwifery students had the opportunity to practice their clinical skills and information sharing of evidence-informed practice. The students were able to move away from the rushed and common 'tick box' mentality that is often found in busy clinical environments and concentrate on demonstrating an accumulation of skills that underpinned quality woman centred care. The student led clinic provided ample time for students to develop trusting longitudinal relationships with women through their continuity of midwifery care experience. Developing professional and clinical 'capacity' is vitally important to the successful preparation of midwives for practice. The extra time awarded to the student supported the, (12) facilitation and development of new knowledge, as well as providing the time and cognitive space to let the knowledge fall into practice. This highlights the importance of ensuring quality clinical experiences for students and why working in the clinic was so beneficial for students. The more students were exposed to this specific learning environment the more they grew in self-confidence which, as Lizzio and Wilson (13) concur, is a key aspect of developing capability.

Midwifery students also developed a sense of professional capability by having the responsibility of managing the appointment and care pathway themselves for women and in collaboration with women. Being afforded the opportunity to take on the role of the primary carer within a supportive environment, offered the midwifery students a chance to test out their capabilities of being the midwife they espoused to be, and enact effective responses to familiar and or new situations. These findings also resonate with the work of Australian researchers Gray, Leap (14). They similarly found that where students were involved with women in the real world, they not only learned clinical skills but also professional attitudes and behaviours. It seems the student led clinic provided the students with a powerful and engaging experience that expanded their expertise and professional identity (15). The experience became part of their personal narrative of being challenged to consider how their practice aligned with the 
values of the midwifery profession. Findings from this study resonate with Sidebotham, Fenwick (16) study which found that if midwifery students were able to practice in supportive environments supported and supervised by an experienced midwife practitioner, they were able to 'discover the midwife they wanted to be'.

Working with the women in a continuity of care relationship, with the support of their practice lecturer, facilitated a great sense of autonomy for the student. Rather than just 'observing', something which students said often happened when following a $\mathrm{CoC}$ woman through the fragmented system, students felt able to take on, and practice, all aspects of the clinical care becoming familiar with the woman's journey and the provision of woman centred holistic midwifery care. Having the autonomy, within the clinic, to practice woman centred care that aligned with their midwifery expectations, beliefs, values and ideals was highly valued by the students. They found this was important for their learning, as they had the opportunity to develop their sense of self as a midwife. Sidebotham, Fenwick (16) also reported that when students had exposure to 'real life' experiences where they could practice the art and science of midwifery during clinical placements such as in a student led clinic, it allowed students to realise the important role that midwives play in facilitating positive outcomes for women. Ultimately preparing them well for their transition to practice.

This outcome is in contrast to the experience of some midwifery students undertaking their $\mathrm{CoC}$ experiences within highly medicalised fragmented maternity units where they have little agency to advocate for women and enact the role and responsibilities of being a midwife (14). As a consequence, student midwives like their registered counterparts, often experience a sense of dissonance between how they believed they should and could be practicing and what they are actually doing in their clinical practice. This leads to disempowerment and a great sense of dissatisfaction $(2,14,17)$. However, the findings do need to be interpreted within the limitations of the study. The study was undertaken at one university in South East Queensland with a relatively small group of midwifery students. As such no generalisations can be made. 


\section{Conclusion and Recommendations}

There is a growing body of work around midwifery students and the continuity of care experience within pre-registration programs. What is becoming increasingly evident from available literature is that students may not be getting as much from their continuity of care experience when undertaken within a fragmented medicalised model (14). The findings of this small study suggest that the student led clinical model enhanced the student's experience of providing continuity of midwifery care to women during the antenatal and postnatal period. Along with embedding students within midwifery continuity of care models, universities and their industry practice partners need to explore the student led clinic model as a way of increasing the number of quality clinical placements that align with the midwifery philosophy. Midwifery clinical placements need to provide students with every opportunity to integrate theory and practice and develop a sense of capability, purpose, resourcefulness, connection and professional identity; all of which are fundamental to graduate success $(16,18,19)$.

Certainly, the findings of this small but rich qualitative study demonstrates that the student led clinic is one model that could improve the clinical experience for midwifery students and reduce the theory-practice gap $(8,20)$. The student led clinic model also supports a learning environment that enhances a positive midwife lecturer-student relationship with an emphasis on hands-on learning. It also provides an opportunity to work with midwives who imbue similar philosophies, rather than becoming desensitized into a midwifery culture that is at odds with the universities philosophy (21). In conclusion, outcomes from this small but rich qualitative descriptive study have the potential to influence and inform midwifery education programs both within and outside of Australia.

Maxwell et al.(1) proclaim that the practice lecturer role is not only essential for enhancing quality practice learning experiences for student midwives, but also has the added benefit of 
supporting midwifery staff in their preceptorship role. In general, there is a need for further exploration into the midwifery lecturer role within the clinical learning environment and the influence it has on a student's experience and learning in the clinical learning environment (21). It is also anticipated that findings from this study will inform midwifery practitioners on how best to enhance the student learning experience within a Continuity of Care model framework.

It is recommended that other universities both within Australia and overseas consider implementing student led clinics within maternity and community settings to provide quality learning environments. As demonstrated in the outcomes from this small study, such models are extremely beneficial for the professional development and clinical preparation of midwifery students.

\section{Acknowledgements and Disclosures}

This study was undertaken as part of an Honours Master's program. We gratefully acknowledge the contribution of the students and midwives who gave freely of their time to participate in the interviews. 


\section{References}

1. Maxwell E, Black S, Baillie L. The role of the practice educator in supporting nursing and midwifery students' clinical practice learning: An appreciative inquiry. Journal of Nursing Education and Practice. 2014;5(1):35.

2. Carter AG, Wilkes E, Gamble J, Sidebotham M, Creedy DK. Midwifery students' experiences of an innovative clinical placement model embedded within midwifery continuity of care in Australia. Midwifery. 2015;31(8):765-71. doi: 10.1016/j.midw.2015.04.006. PubMed PMID: 2013054872. Language: English. Entry Date: 20150807. Revision Date: 20150807. Publication Type: journal article.

3. Colorafi KJ, Evans B. Qualitative Descriptive Methods in Health Science Research. HERD:

Health Environments Research \& Design Journal. 2016;9(4):16-25. doi: 10.1177/1937586715614171.

4. Schneider Z, Whitehead D. Nursing and midwifery research: methods and appraisal for evidence-based practice. 5th, Australia and New Zealand ed. Chatswood, N.S.W: Elsevier Australia (a division of Reed International Books Australia Pty Ltd); 2016.

5. Petty NJ, Thomson. Ready for a paradigm shift? Part 2: Introducing qualitative research methodologies and methods. Manual therapy. 2012;17(5):378-84.

6. Vaismoradi M, Turunen $\mathrm{H}$, Bondas T. Content analysis and thematic analysis: Implications for conducting a qualitative descriptive study. Nursing \& Health Sciences. 2013;15(3):398-405. doi: 10.1111/nhs.12048.

7. Sandelowski M. What's in a name? Qualitative description revisited. Research in Nursing and Health. 2010;33(1):77-84. doi: 10.1002/nur.20362.

8. Miller S, Thompson J, Sonneborn O, McGuiness W. THE ROLE OF THE LECTURERPRACTITIONER IN BRIDGING THE THEORY-PRACTICE GAP IN POSTGRADUATE EDUCATION. Australian Nursing and Midwifery Journal. 2017;25(2):37.

9. Manninen K, Welin Henriksson E, Scheja M, Silén C. Authenticity in learning - nursing students' experiences at a clinical education ward. Health Education. 2013;113(2):132-43. doi: 10.1108/09654281311298812.

10. Blackmore C. Towards a Pedagogical Framework for Global Citizenship Education. International Journal of Development Education and Global Learning. 2016;8(1):39.

11. Lofstrom E, Nevgi A. University teaching staffs' pedagogical awareness displayed through ICT-facilitated teaching. Interactive learning environments. 2008;16(2):101-16.

12. Andersson PL, Edberg A-K, Högskolan $\mathrm{K}$, Sektionen $\mathrm{s}$. The nursing programme in the rearview mirror. Interviews with Swedish nurses one year after their graduation. Nurse Education Today. 2010;30(8):747-51. doi: 10.1016/j.nedt.2010.01.017.

13. Lizzio A, Wilson K. Action Learning in Higher Education: an investigation of its potential to develop professional capability. Studies in Higher Education. 2004;29(4):469-88. doi:

10.1080/0307507042000236371.

14. Gray J, Leap N, Sheehy A, Homer CSE. Students' perceptions of the follow-through experience in 3 year bachelor of midwifery programmes in Australia. Midwifery. 2013;29(4):400-6. doi: http://dx.doi.org/10.1016/j.midw.2012.07.015.

15. Leiman T, Ankor D, Milne J. Beginning in the first year: Towards a vertically integrated curriculum for clinical legal education. A Practice Report. The International Journal of the First Year in Higher Education. 2015;6(1):171-7. doi: 10.5204/intjfyhe.v6i1.261.

16. Sidebotham M, Fenwick J, Carter A, Gamble J. Using the five senses of success framework to understand the experiences of midwifery students enroled in an undergraduate degree program.

Midwifery. 2015;31(1):201-7. doi: 10.1016/j.midw.2014.08.007.

17. Gilmour C, McIntyre M, McLelland G, Hall H, Miles M. Exploring the impact of clinical placement models on undergraduate midwifery students. Women and Birth. 2013;26(1):e21-e5. doi: 10.1016/j.wombi.2012.06.004. 
18. Lizzio A. Succeeding @ Griffith: Next Generation Partnerships across the Student Lifecycle. 2011.

19. Bass J, Walters C, Toohill J, Sidebotham M. Promoting retention, enabling success: Discovering the potential of student support circles. Nurse Education in Practice. 2016;20:109-16. doi: https://doi.org/10.1016/j.nepr.2016.07.002.

20. Wilson J. Bridging the Theory Practice Gap. Australian Nursing Journal: ANJ, The. 2008;16(4):25.

21. Licqurish S, Seibold C. Bachelor of Midwifery students' experiences of achieving competencies: The role of the midwife preceptor. Midwifery. 2008;24(4):480-9. doi: http://dx.doi.org/10.1016/j.midw.2007.05.001.

Table 1: Participant characteristics

\begin{tabular}{|l|l|l|l|l|}
\hline Participant & Pseudonym & Age & Previous Qualification & Registered or \\
student midwife
\end{tabular}

